\title{
RESUMO
}

ISSN Digital: 2316-3801

ISSN Impresso: 2316-3348

DOI: 10.17564/2316-3801.2019v7n3p47-56

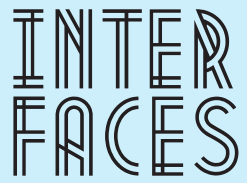

CIENTÍFICAS

\section{CONSUMO MIDIÁTICO DE JOVENS: UMA INCURSÃO NO INTERIOR SERGIPANO}

MEDIA CONSUMPTION OF YOUNG PEOPLE: AN INCURSION INTO SERGIPE COUNTRYSIDE

CONSUMO MEDIÁTICO DE JÓVENES:

UNA INCURSIÓN ENEL INTERIOR SERGIPANO
Matheus Pereira Mattos Felizola Vitor José Braga Mota Gomes²

Flávio Costa de Mendonça ${ }^{3}$ Caio Mário Guimarães Alcântara ${ }^{4}$
A considerar um contexto de imersão entre as mídias e o cotidiano das pessoas, entender o consumo midiático dos sujeitos é uma forma de perceber os impactos e alterações promovidos pelos meios de comunicação. Com o intuito de compreender o consumo midiático de jovens da zona urbana e rural entre 18 e 24 anos num cenário de convergência com as redes sociais, foi desenvolvido o projeto "Jovens e Consumo Midiático em Tempos de Convergência: Brasil Profundo". A pesquisa, de cariz qualitativa e de método etnográfico, foi realizada em três estados brasileiros e teve uma de suas fases desenvolvidas no município sergipano de Amparo de São Francisco, onde foram aplicadas entrevistas não estruturadas e observação participante. Constatou-se que os jovens participantes do estudo são ativos nas mídias, engajando-se, principalmente, por meio de redes sociais e aplicativos para dispositivos móveis. Além disso, possuem um forte senso de pertença ao ecúmeno, mesmo que não visualizem grandes perspectivas de vida ao permaneceram na cidade pesquisada.

\section{PALAVRAS-CHAVE}

Consumo Cultural. Consumo Midiático. Jovens. Convergência. 


\section{ABSTRACT}

Considering a context of immersion between the media and the daily life of the people, understanding the media consumption of the subjects is a way of perceiving the impacts and changes promoted by the media. In order to understand the media consumption of young people from urban and rural areas between 18 and 24 years of age, in a scenario of convergence with social networks, the project "Youth and Media Consumption in Times of Convergence: Deep Brazil" was developed. The qualitative and ethnographic research was carried out in three Brazilian states and one of its phases was developed in the city of Amparo de São Francisco, where unstructured interviews and participant observation were applied. It was found that the young people participating in the study are active in the media, engaging mainly through social networks and applications for mobile devices. In addition, they have a strong sense of belonging to the ecumene, even if they do not visualize great perspectives of life when they remained in the researched city.

\section{KEYWORDS}

Cultural Consumption. Media Consumption. Youth. Convergence.

\section{RESUMEN}

A considerar un contexto de inmersión entre los medios y el cotidiano de las personas, entender el consumo mediático de los sujetos es una forma de percibir los impactos y alteraciones promovidos por los medios de comunicación. Con el fin de comprender el consumo mediático de jóvenes de la zona urbana y rural entre 18 y 24 años en un escenario de convergencia con las redes sociales, se desarrolló el proyecto “Jóvenes y Consumo Mediático en Tiempos de Convergencia: Brasil Profundo”. La investigación, de carácter cualitativo y de método etnográfico, fue realizada en tres estados brasileños y tuvo una de sus fases desarrolladas en el municipio sergipano de Amparo de San Francisco, donde se aplicaron entrevistas no estructuradas y observación participante. Se constató que los jóvenes participantes del estudio son activos en los medios, comprometiéndose principalmente a través de redes sociales y aplicaciones para dispositivos móviles. Además, poseen un fuerte sentido de pertenencia al ecúmeno, aunque no vean grandes perspectivas de vida al permanecer en la ciudad investigada.

\section{PALABRAS CLAVE}

Consumo cultural. Consumo mediático. Jóvenes. Convergencia. 


\section{INTRODUÇ̧̃̃o}

A ideia de investigar o Brasil Profundo surge com a concepção apresentada pelo antropólogo Batalla (1989), que avaliou a história da civilização mexicana e observou a negação da cultura indígena a partir da colonização espanhola nas populações das cidades. No Brasil, esse conceito foi utilizado para o desenho da pesquisa "Jovens e Consumo Midiático em Tempos de Convergência: Brasil Profundo", realizado por equipes em três estados, nomeadamente Rio Grande do Sul, Pará e Sergipe. A proposta desenvolvida no Brasil, contudo, diferencia-se na medida em que foi proposta uma análise sobre a relação dos sujeitos com as mídias nas populações mais distantes da influência das grandes cidades, aquelas que vivem em comunidades quilombolas, aldeias indígenas e povoados da zona rural.

A pesquisa aqui descrita, de natureza qualitativa (BOGDAN; BICKLEN, 2013), corresponde à segunda fase da investigação nacional, quando os pesquisadores de cada estado realizaram um estudo piloto em apenas um município, para verificar as condições de aplicabilidade de instrumentos como diário de bordo e tópicos de entrevistas (por não serem estruturadas, as entrevistas deste estudo não têm roteiro, mas tópicos de assuntos). Os resultados dessa fase, além de possibilitarem reflexões sobre a necessidade de alterar alguns elementos para as terceira etapa (ainda em desenvolvimento num número mais alargado de municípios), proporcionaram dados sobre como a população alvo do estudo, jovens com idades entre 18 e 24 anos relaciona-se com as mídias no município de Amparo de São Francisco, interior de Sergipe.

0 trabalho relativo a essa fase teve duração de sete meses, sendo a pesquisa iniciada em setembro de 2016 e finalizada em fevereiro de 2017. Toda a análise dos dados colhidos leva em conta quatro eixos teóricos: i) convergência midiática a partir da discussão cultural e tecnológica proposta por Jekins (2009); ii) consumo cultural na perspectiva da desterritorizalização de Canclini (2008); iii) microcultura de Anderson (2008); e iv) consumo midiático, a partir da visão de Canclini (1993).

Para além desta introdução, o presente artigo conta com as seguintes seções: a) do consumo midiático à convergência dos meios (embasamento teórico da pesquisa e da análise); b) procedimentos metodológicos (detalhamento do processo de recolha de dados); c) Resultados e discussões (com a contextualização de dados geográficos do município de Amparo de São Francisco e discussão dos dados das entrevistas); e d) considerações finais.

\section{DO CONSUMO MIDIÁTICO À CONVERGÊNCIA DOS MEIOS}

Conforme Jacks e "outros autores” (2014b) consumo midiático refere-se à relação estabelecida entre o indivíduo e o que a mídia oferece em termos de produtos (novelas, filmes, moda, publicidade, notícias etc.). Esse consumo tende a moldar a forma como os indivíduos se comportam e interagem com a sociedade, sendo entendido como um elemento produtor de modos de ser (FISCHER, 2002), especialmente se considerado o momento de forte virtualização das atividades humanas, quando as sociedades tendem a migrar suas interações para espaços midiatizados (CASTELLS et al., 2009). 
A relação cada vez consolidada entre a mídia e o cotidiano embasa a necessidade de estudo sobre o consumo midiático, que se difere do estudo de recepção na medida em que é direcionado para "a relação com os meios e não com as mensagens, para usar uma imagem simplificada do processo" (JACKS; TOALDO, 2013, p. 7-8). Essa é uma visão compactuada por Canclini (2008), para quem "os jovens adquirem nas telas extracurriculares uma formação mais ampla em que conhecimento e entretenimento se combinam" (CANCLINI, 2008, p. 23).

Estudar o consumo midiático seria, portanto, conhecer como se processam as relações com dispositivos digitais e compreender as transformações na maneira de consumir, em especial entre jovens. No Brasil, alguns estudos já mostram, por exemplo, que a preferência pela TV tem caído entre o público deste estudo (jovens com idades entre 18 e 24 anos) e a opção da internet se tornou 25\% maior, principalmente por possibilitar o acesso a diferentes mídias numa só plataforma, funcionando como vetor de convergência (BRASIL, 2014).

A partir do conceito de convergência midiática, pode-se compreender como o consumo midiático dos jovens passa por mudanças. Jenkins (2009) defende ser possível avaliar a convergência como uma manifestação cultural da sociedade. A cultura da convergência permite que planejamento de agências gigantes como Y\&R, Ogilvy \& Mather e WMcCann colidam com o fluxo de uma comunidade quilombola em Amparo de São Francisco.

Ainda dentro da discussão, torna-se importante pensar na cultura participativa (JEKINS, 2009) como efeito do surgimento de um novo indivíduo e em paralelo com a figura do prosumer(BÓRIO, 2014). Esse novo indivíduo não apenas consome os produtos midiáticos, mas interfere, critica e cria, características potencializadas por mídias como a internet, que concedem (ainda que hipoteticamente) a cidadãos de Amparo de São Francisco as mesmas condições de acesso e participação concedidas a cidadãos de qualquer grande centro do mundo. Jenkins (2009), contudo, lembra que "alguns consumidores têm mais habilidades para participar dessa cultura emergente do que outros” (JENKINS, 2009, p. 31).

Enquanto espaço on-line, a mídia social é embasada na tríade interação, colaboração e criação de conteúdo. A Mídia Social não existiria sem a troca coletiva na rede. Ela pode representar $1 \%$ de produtores, $10 \%$ de comentadores e $89 \%$ de leitores, mas com a consolidação das redes sociais na internet vê-se a possibilidade emergente da rede, seja escrevendo, enviando imagens, músicas ou abrindo um canal próprio, o que tem relação direta com o consumo de mídia e se constitui como foco deste artigo.

\section{PROCEDIMENTOS METODOLÓGICOS}

A pesquisa configura-se como qualitativa (BOGDAN; BICKLEN, 2013) do tipo etnográfico (AGROSINO, 2008). Como relatado, este artigo descreve e discute o processo e resultado da segunda fase do estudo “Jovens e Consumo Midiático em Tempos de Convergência: Brasil Profundo” em Sergipe. Uma vez discutidos e definidos os referenciais teóricos da pesquisa (primeira fase), as equipes de cada estado deveriam reunir-se para escolher um município e produzir os instrumentos de coleta a serem utilizados na segunda fase. Essa segunda fase, por sua vez, consistiu na aplicação dos instrumentos

Interfaces Científicas - Humanas e Sociais - Aracaju • V.8 - N.1 • p. 123 - 132 - Abril/Maio/Junho - 2019 
como estudo piloto. Em Sergipe, o município escolhido foi Amparo de São Francisco, por ser uma cidade distante dos grandes centros, contar com população urbana e quilombola.

Foram realizadas reuniões para formular um roteiro de entrevista composto por tópicos de interesse e não sugestões de perguntas. A escolha desse tipo de roteiro se deu pelo fato de que tal modelo permite uma organização flexível e a ampliação dos questionamentos à medida que a informação é fornecida pelos entrevistados (FUJISAWA, 2000), natureza da entrevista em profundidade, abordagem definida para a pesquisa (BOGDAN; BIKLEN, 2013). A formulação do roteiro contou com uma etapa de teste, realizado com jovens da mesma faixa etária de interesse da pesquisa, estudantes da Universidade Federal de Sergipe (UFS), que conta com muitos estudantes vindos de comunidades rurais e quilombolas do interior do estado.

Uma vez definido e aprovado o roteiro, a etapa de campo da fase passou a ser executada. Inicialmente, um grupo de pesquisadores estabeleceu contato com jovens lideranças de Amparo de São Francisco (jovens envolvidos com grupos religiosos, partidos políticos, líderes estudantis etc.). Esse contato foi feito via redes sociais e possibilitou a apresentação da pesquisa e solicitação de ajuda para mobilização de outros jovens.

Com esse contato estabelecido, o grupo viajou até o município em duas viagens distintas e passou dois dias em cada uma das viagens, coletando imagens, conhecendo os contextos locais e colhendo algumas entrevistas. Essa imersão serviu para fortalecer a integração dos pesquisadores com a comunidade, algo essencial para o sucesso de uma pesquisa etnográfica (AGROSINO, 2008). Todo esse processo foi documentado em diário de bordo do pesquisador e gravado em áudio. As informações coletadas serviram para a reformulação dos roteiros de entrevistas, com inclusão de alguns tópicos.

A terceira ida a Amparo de São Francisco consistiu na coleta definitiva de entrevistas. Durante os dois dias foram entrevistados jovens da sede do município e do povoado Lagoa dos Campinhos. Também foram realizados discussões em grupos compostos por jovens voluntários (com idade inferior à de interesse do estudo, líderes religiosos e uma professora). Todas as entrevistas, assim como a reunião do grupo, só ocorreram após a apresentação e assinatura do Termo de Consentimento Livre e Esclarecido (TCLE).

Os procedimentos foram gravados e transcritos pelos integrantes do grupo de pesquisa. As gravações foram efetuadas com um gravador profissional e também com os celulares dos pesquisadores. Os conteúdos foram cruzados com as informações dos diários de bordo e constituem a análise aqui contida.

\section{RESULTADOS E DISCUSSÕES}

Amparo do São Francisco é um município com 2.275 mil habitantes (IBGE, 2010), localizado na região do Baixo São Francisco em Sergipe. Faz fronteira com os municípios de Cedro de São João, Telha e Canhoba, estando a 116 km da capital do estado. Em termos econômicos, o município tem três principais atividades: pesca (principal atividade e fonte de renda das famílias), agricultura (familiar e limitada devido aos grandes períodos de seca) e serviços (algumas microempresas e ati- 
vidades relacionadas ao serviço público, sendo a Prefeitura Municipal a principal empregadora). 0 município tem, segundo o IBGE (2010), um PIB per capta de pouco mais de nove mil reais, estando abaixo da média estadual e nacional.

Em termos culturais, o município tem hoje uma divisão clara entre as populações jovens da zona urbana (parte central) e populações quilombolas. Os jovens da zona urbana são de religiões cristãs (católicos ou evangélicos) e afirmam uma percepção negativa sobre os jovens quilombolas, praticantes de religiões não cristãs e de matriz africana. Esses jovens são ligados à família, muitos deles trabalham e vivem com os pais, mesmo os que já tenham as próprias famílias constituídas.

A rede municipal de educação conta com três escolas de ensino fundamental e Educação de Jovens e Adultos (EJA) na sede do município, onde também funciona um polo de educação a distância Instituto Federal de Sergipe (IFS, on-line), mas não há computadores para o uso dos alunos 5 . $\mathrm{Na}$ zona rural ficam localizadas outras quatro escolas, sendo que nenhuma delas oferece o acesso à internet aos estudantes.

Em se tratando de acesso à internet, Amparo de São Francisco conta com três principais formas: internet via rádio (com sinal fornecido por uma empresa do município de Propriá), rede móvel (sendo a mais utilizada a rede da empresa $\mathrm{Oi}$, com sinal $3 \mathrm{~g}$ ) e satélite (serviço de canais por assinatura). Segundo os jovens que participaram do estudo, o uso da internet é, na maior parte das vezes, voltado para o entretenimento.

O grupo dos jovens entrevistados é composto por oito indivíduos (quatro deles com 19 anos, dois com 23 anos, um com 18 e outro com 21 anos), sendo três do sexo masculino e cinco do sexo feminino. Desses jovens apenas um possui o ensino superior completo, dos demais três estão cursando o ensino superior, outros três concluíram o ensino médio, e apenas um não concluiu o ensino médio. Um desses jovens abriu seu próprio negócio na cidade, enquanto outros dois trabalham informalmente no próprio município, um ensinando banca para os mais jovens na cidade e outro, trabalhando com produção de artesanato (bordado) e com cuidados de idosos. Os demais disseram estar à espera de oportunidades.

Quase todos os participantes do estudo são católicos, ou frequentadores da igreja, com apenas um deles tendo se declarado ateu. Entre as principais expectativas para o futuro apenas o jovem que abriu empresa em Amparo de São Francisco deseja permanecer na cidade, os demais desejam sair, preferencialmente, para a capital, Aracaju.

Em relação às práticas de consumo midiáticas desses jovens, todos afirmaram utilizar a internet para fazer uso das redes sociais, cinco deles também afirmaram utilizar bastantes os sites de pesquisa, filmes, séries. Palestras on-line também foram citadas por eles. Três deles afirmaram passar o dia inteiro utilizando a internet, a maioria fazia uso de 3 a 12 horas diariamente, enquanto apenas um afirmou que utilizava por alguns minutos, sem muita frequência.

Essa utilização cada vez mais irrestrita (atividades com fins de diversão, estudo, trabalho, serviços burocráticos etc.) estão em consonância com o pensamento de Castells e "outros autores" (2009), para quem esse é um processo comum e cada vez mais evidente na sociedade. Neste sentido, compre-

5 Disponível em: http://guia-sergipe.escolasecreches.com.br/educacao-de-jovens-e-adultos-ensino-fundamental/ESCOLA-MUNICIPAL-IVANY-DA-GLORIA-FREIRE-amparo-de-sao-francisco-amparo-de-sao-francisco-sergipe-i28012674.htm .

Acesso em 26 de abr. de 2017 
ende-se que os jovens que participaram dessa fase da pesquisa aqui descrita estão em conformidade com o pensamento referido.

O celular é o meio de acesso utilizado por todos eles, mas o computador de mesa e o notebook também são citados. Dois entrevistados afirmaram fazer uso somente do celular para acessar a internet, o que evidencia o contributo dos smartphones para a popularização do acesso à internet, dado que aproxima o resultado obtido com as entrevistas aplicadas em Sergipe com os dados nacionais de acesso à internet pelos jovens (BRASIL, 2014).

No que tange as formas de acesso, a maioria faz uso da rede móvel, mas a internet via rádio e satélite também são citadas. Em relação às principais redes sociais consumidas por eles, o Facebook foi mencionado por todos, o WhatsApp e o Instagram também são citados pela maioria, mas é interessante perceber que algumas redes como Snapchat e Twitter, ainda sobrevivem na cidade, mesmo não sendo mais tão fortes como outrora.

Esses jovens seguem dentro de suas redes sociais principalmente perfis de artistas e celebridades. Desta forma, as FanPages se destacam, também, nos principais conteúdos curtidos por eles, além das fotos de amigos. Eles costumam, além de seguir, comentar nas fotos publicadas e participar de debates dentro das páginas. Os que interagem mais nas redes sociais acabam criando vínculos com pessoas de outras cidades, a maioria da mesma região.

Em sua maioria, eles costumam postar fotos (selfies, fotos da família ou da natureza), mas opiniões e questões políticas também são citadas. A maioria deles afirma postar conteúdos com bastante frequência, mostrando que esse jovem não está somente consumindo conteúdo, está também produzindo (alguns diariamente), o que comprova o entendimento de Jenkis (2009) e Bório (2014) ao falarem sobre a mudança dos indivíduos frente aos conteúdos das redes.

0 uso do celular nos mais diversos momentos é feito em concomitância com outras ações, tais como assistir à televisão, estudar e trabalhar. Não existe uma motivação em comum por partes dos jovens entrevistados para a utilização das redes sociais, sendo citada a interação com outros jovens e o acesso a informação como os principais motivos.

Neste aspecto justificam-se as pesquisas sobre o consumo midiático de jovens. Eles têm um acesso cada vez mais facilitado a dispositivos e à rede, e os conteúdos lá postados têm contribuído com a formação desses indivíduos. Conhecer a maneira como esses jovens relacionam-se com a cultura é uma forma de garantir orientação para um uso que possibilite a formação de cibercidadãos, pessoas que saibam utilizar a internet não somente para diversão, mas para exercer deveres e lutar por seus direitos.

\section{CONSIDERAÇÕES FINAIS}

A pesquisa teve resultados em três grandes eixos: i) compreensão teórica e prática do consumo midiático entre os jovens; ii) conhecimento da realidade sociocultural do município; e iii) desenho metodológico do estudo. Cada um contribuindo para o crescimento dos pesquisadores, ampliação e aprofundamento da discussão proposta. 
O contato com os jovens do município de Amparo de São Francisco possibilitou compreender o fenômeno do consumo midiático por uma nova perspectiva. Muito mais que indivíduos manipulados pelos meios de comunicação, o que os membros do grupo encontraram foi uma população jovem muito ativa em termos de produção na internet que sabe buscar conteúdo e são engajados. A questão a considerar é que eles apenas utilizam esses conteúdos para a diversão, reduzindo as possibilidades formativas e de desenvolvimento (pessoal, econômico etc.) inerentes à internet.

O domínio de utilização dessas redes é devido, principalmente, ao acesso quase constante a espaços como o Facebook e o WhastApp. Essa é outra questão a ser tratada, visto que para alguns dos participantes do estudo, o uso de smartphones para acessar a internet é quase um vício, o que precisa ser mais estudado para que se possa sugerir caminhos e soluções.

No que se refere à realidade do município de Amparo de São Francisco, a pesquisa permitiu concluir que há poucos dados atualizados e cientificamente embasados sobre a história e geografia da região, o que justificou a elaboração de um dossiê sobre os municípios da microrregião de Propriá (ainda em produção). Apesar da ausência de dados oficiais, percebeu-se que o município é pobre do ponto de vista econômico e não oferece oportunidades de desenvolvimento para os jovens, com poucas perspectivas de crescimento educacional e profissional.

Do ponto de vista metodológico, a realização do estudo aqui descrito permitiu um conhecimento prático sobre a pesquisa etnográfica, com todas as dificuldades e contingências do processo. Além do mais, foi possível visualizar as vantagens de aplicar a pesquisa para um grupo menor antes de efetivar o estudo em um grupo mais abrangente. Foi com o percurso desta pesquisa em Amparo de São Francisco que o grupo pôde perceber as facilidades advindas de conhecer os contextos culturais de cada município antes de deslocar-se, ter contatos com lideranças locais e imersão com os sujeitos da investigação.

Com esses resultados, bem como com as análises advindas dos dados obtidos em Amparo de São Francisco, foi possível definir novas metas e procedimentos a adotar na terceira fase do estudo (ainda em desenvolvimento), que vai ouvir jovens de outros nove municípios da região (um total previsto de 250 questionários e 100 entrevistas) e da capital, Aracaju.

\section{REFERÊNCIAS}

ANDERSON, C. A cauda longa: do mercado de massa para o mercado de nicho. 2. ed. São Paulo: Alta Books, 2008.

ANGROSINO, M. Etnografia e observação participante. Porto Alegre: Artmed, 2008

BATALLA, G. B. México profundo: una civilización negada. 2. ed. Miguel Hidalgo: Editorial Grijalbo, 1989.

BOGDAN, R.; BICKLEN, S. Investigação qualitativa em educação: uma introdução à teoria e aos métodos. Porto: Porto Editora, 2013 
BÓRIO, P. M. C. Prosumer: o novo protagonista da comunicação. 2014. Dissertação (Mestrado) Programa de Pós-Graduação em Comunicação, Universidade Federal da Paraíba, João Pessoa, PB, 2014.

BRASIL. Presidência da República. Hábitos de consumo de mídia pela população brasileira. Brasília: SECOM, 2014.

CANCLINI, N. G. El consumo cultural en México. México: Grijalbo, 1993.

CANCLINI, N. G. Leitores, espectadores e internautas. São Paulo: Iluminuras, 2013.

CANCLINI, N. G. Culturas híbridas: Estratégias para entrar e sair da modernidade. 5. ed. São Paulo: EDUSP, 2013.

CASTELLS, M. et al. Comunicação móvel e sociedade: uma perspectiva global. Lisboa: Fundação Calouste Gulbenkian, 2009.

FISCHER, R. M. B. Dispositivos pedagógicos da mídia: modos de educar na (e pela) TV. Educação e Pesquisa, São Paulo, v. 28, n. 1, p. 151-162, jan./jun. 2002.

FUJISAWA, D. S. Utilização de jogos e brincadeiras como recurso no atendimento fisioterapêutico de criança: implicações na formação do fisioterapeuta. 2000. Dissertação (Mestrado em Educação) - Faculdade de Filosofia e Ciências, Universidade Estadual Paulista, Marília, SP, 2000.

INSTITUTO BRASILEIRO DE GEOGRAFIA E ESTATÍSTICA. 2010. IBGE. Disponível em: https://ww2.ibge.gov.br/. Acesso em: fev. 2019.

IFS - Instituto Federal de Sergipe. Educação a Distância (EAD). Disponível em: http://www. ifs.edu.br/ead/index.php?option=com_contentধview=articleধid=135 Acesso em: 26 abr. de 2017

JACKS, N., TOALDO, M. Consumo midiático: uma especificidade do consumo cultural, uma antessala para os estudos de recepção. Encontro da Compós, 22, 2013, Salvador. Anais [...], Salvador, BA, 2013.

JACKS, N. et al. Jovem e consumo midiático: dados preliminares do estudo piloto e da pesquisa exploratória. Encontro Anual da Associação Nacional dos Programas de Pós-Graduação em Comunicação, 23. Anais [...], 2014.

JENKINS, H. Cultura da convergência. Tradução Suzana Alexandria. 2. ed. São Paulo: Aleph, 2009. 432p. 
1 Professor do Programa de Pós-Graduação em Comunicação e do Mestrado Profissional em Ciência da Informação na Universidade Federal de Sergipe - UFS; Professor do Curso de Publicidade e Propaganda da UFS; Doutor em Ciências Sociais pela Universidade Federal do Rio Grande do Norte - UFRN; Líder do Grupo de Pesquisa em Empreendedorismo e Inovação e Vice-líder do Grupo de Pesquisa em Marketing.

E-mail: matheus.felizola.marketing@gmail.com

2 Professor do Programa de Pós-Graduação em Comunicação e do Departamento de Comunicação Social da Universidade Federal de Sergipe - UFS; Doutor em Comunicação e Cultura Contemporânea pela Universidade Federal da Bahia - UFBA; Coordenador do Grupo de Pesquisa em Marketing. E-mail: vitorbragamg@gmail.com

3 Mestre em Comunicação pela Universidade Federal de Sergipe - UFS; Graduado em Comunicação Social Publicidade e Propaganda pela UFS; Membro do Grupo de Pesquisa em Marketing.

E-mail: flaviocostadmendonca@gmail.com

4 Doutorando em Educação pela Universidade de Aveiro - UA; Membro do Grupo de Investigação em Avaliação, Política e Qualidade do Centro de Investigação em Didática e Tecnologia na Formação de Formadores - CIDTFF e do Grupo de Pesquisa em Comunicação, Educação e Sociedade - GECES/CNPq. E-mail: caiogmalcantara@gmail.com

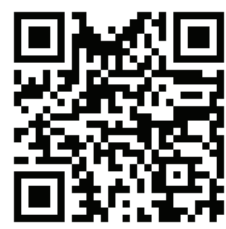

A autenticidade desse artigo pode ser conferida no site https://periodicos. set.edu.br

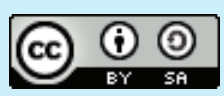

Este artigo é licenciado na modalidade acesso abertosob a Atribuição-Compartilhalgual CC BY-SA

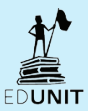

